When recognized postoperatively, the patient's past history of IE, 2 cardiac operations, and poor clinical condition suggested that another reoperation would be high risk, which led to the decision to close the fistula with an Amplatzer device. Failure to close the shunt percutaneously worsened his heart failure and resulted in ascites, intravascular hemolysis, jaundice, and renal failure. Successful cases of transcatheter closure of acquired LV-RA fistulas have been reported, ${ }^{2}$ and device closure was a reasonable option in this patient, although longterm results are unknown. In our case, however, when the device closure had failed and the patient's heart failure worsened, there was little excuse for not referring this young man early to a center with more experience performing complex reoperations.
In conclusion, transcatheter device closure of acquired LV-RA fistulas can be justified and attempted, but if unsuccessful, surgery should be reconsidered early, before the patient becomes inoperable with multiorgan failure.

\section{References}

1. Sinisalo JP, Sreeram N, Jokinen E, Qureshi SA. Acquired left ventricular-right atrium shunts. Eur J Cardiothorac Surg. 2011;39:500-6.

2. Sinisalo JP, Sreeram N, Qureshi SA. Transcatheter closure of acquired left ventricle to right atrium shunts. Catheter Cardiovasc Interv. 2013;82: E809-14.

3. Crawford GB, Brindis RG, Krucoff MW, Mansalis BP, Carroll JD. Percutaneous atrial septal occluder devices and cardiac erosion: a review of literature. Catheter Cardiovasc Interv. 2012;80:157-67.

4. Mello DM, Fahey J, Kopf GS. Repair of aortic-left atrial fistula following the transcatheter closure of an atrial septal defect. Ann Thorac Surg. 2005;80: 1495-8.

\title{
Sternal metastasis of renal cell carcinoma: The role of metastasectomy
}

\author{
Naruhiko Ikoma, MD, and Ara Vaporciyan, MD, Houston, Tex
}

Sternal metastasis of renal cell carcinoma (RCC) has rarely been reported in the literature. ${ }^{1}$ This case series describes the presentation and management of 3 patients with isolated sternal metastasis of RCC treated with sternectomy with curative intent.

\section{CLINICAL SUMMARIES Patient 1}

A 40-year-old man was seen in April 2004 with an enlarging sternal mass. Computed tomography revealed a lytic lesion involving the entire manubrium and a mass in the left kidney. Biopsy of the renal mass revealed an unclassified RCC. Despite chemotherapy, the disease progressed. In October 2004, the patient underwent en bloc chest wall resection of a portion of the sternum, both clavicular heads, and the medial first and second ribs. Reconstruction was performed with Prolene mesh (Ethicon, Inc, Somerville, $\mathrm{NJ})$ and a left pectoralis major muscle flap. The pathology report indicated an $8.5 \times 6.5 \times 6.0-\mathrm{cm}$ metastatic RCC.

From the Thoracic Surgery Department, MD Anderson Cancer Center, Houston, Tex. Disclosures: Authors have nothing to disclose with regard to commercial support.

Received for publication Dec 23, 2013; revisions received April 17, 2014; accepted for publication June 10, 2014; available ahead of print Aug 21, 2014.

Address for reprints: Ara Vaporciyan, MD, Room 19.6008, 1400 Pressler, Houston, TX 77030 (E-mail: avaporci@mdanderson.org).

J Thorac Cardiovasc Surg 2014;148:e230-1

0022-5223/\$0.00

Published by Elsevier Inc. on behalf of The American Association for Thoracic Surgery

http://dx.doi.org/10.1016/j.jtcvs.2014.06.081
In December 2004, left radical nephrectomy was performed, and the pathology report revealed a $6.5-\mathrm{cm}$ unclassified RCC (Fuhrman nuclear grade 3) with invasion into the perinephric adipose tissue and vascular lymphatic spaces. In July 2007, brain and rib metastases were discovered. The patient underwent stereotactic radiosurgery and several craniotomies, followed by chemotherapy; however, the disease progressed, and the patient died in April 2011.

\section{Patient 2}

A 60-year-old man was seen with an enlarging sternal mass in February 2013. Biopsy revealed metastatic RCC, and computed tomography revealed a right kidney tumor. A right radical nephrectomy was performed in May 2013. The histopathologic diagnosis was clear cell RCC (Fuhrman nuclear grade 3). Because of the large size of the sternal metastasis, the patient underwent adjuvant chemotherapy, to which there was partial response. In October 2013, the patient underwent total sternectomy and reconstruction with GORE-TEX mesh (W. L. Gore \& Associates, Flagstaff, Ariz), titanium sternal bars, bilateral pectoralis major flaps, and pedicled right rectus abdominis muscle flap. The pathology report of the sternal lesion revealed an $8.5 \times 7.3-\mathrm{cm}$ metastatic RCC.

\section{Patient 3}

A 47-year-old man was seen with a painful mass at the medial border of his left clavicle. Biopsy in November 
TABLE 1. Characteristics of patients with renal cell carcinoma with reported isolated sternal metastasis

\begin{tabular}{lc}
\hline Total patients & 11 \\
Age $(\mathrm{y})$ & $58.1 \pm 12.6$ \\
Sex (male) & $82 \%(9 / 11)$ \\
Symptoms of sternal mass & $100 \%(11 / 11)$ \\
Biopsy of sternal mass & $70 \%(8 / 11)$ \\
Synchronous metastasis & $91 \%(10 / 11)$ \\
Primary tumor size $(\mathrm{cm})$ & $4.6 \pm 1.7$ \\
Sternal tumor size $(\mathrm{cm})$ & $6.7 \pm 1.9$ \\
Operation & \\
$\quad$ Nephrectomy & $100 \%(11 / 11)$ \\
Partial sternectomy & $73 \%(8 / 11)$ \\
Total sternectomy & $9 \%(1 / 11)$ \\
$\quad$ Palliative radiation & $18 \%(2 / 11)$ \\
Manubrium resected & $75 \%(6 / 8)$ \\
Involved rib levels & $2.2 \pm 0.4$ \\
Reconstruction & \\
$\quad$ Mesh & $67 \%(6 / 9)$ \\
Bar & $11 \%(1 / 9)$ \\
Pectoralis muscle flap & $33 \%(3 / 9)$ \\
Rectus abdominis muscle flap & $22 \%(2 / 9)$ \\
Operative complication & \\
Respiratory & \\
Wound infection & $0 \%(0 / 9)$ \\
Osteochondritis & $11 \%(1 / 9)$ \\
Perioperative systemic therapy & $11 \%(1 / 9)$ \\
Perioperative radiation therapy & $22 \%(2 / 9)$ \\
\hline
\end{tabular}

2011 revealed metastatic RCC. Computed tomography showed a left kidney mass. Left nephrectomy was performed, and clear cell RCC (diameter, $5.8 \mathrm{~cm}$; Fuhrman nuclear grade 3) with invasion into renal sinus vessels was revealed. Two weeks later, the patient underwent resection of the left clavicle and part of the manubrium; metastatic RCC (diameter, $4.5 \mathrm{~cm}$ ) was revealed. In February 2012, short-interval local recurrence in the manubrium was discovered, and repeat partial manubriectomy and resection of left infraclavicular soft tissue mass were performed. After another recurrence in the manubrium in November 2013, the patient was referred to the MD Anderson Cancer Center, where he underwent complete manubriectomy without reconstruction. Pathology revealed metastatic RCC (diameter, $3.8 \mathrm{~cm}$ ). The patient's recovery was complicated by a surgical site infection and asymptomatic bilateral pulmonary embolisms. He underwent percutaneous drainage with resolution and also underwent therapeutic anticoagulation.

\section{DISCUSSION}

Sternal metastasis has frequently been reported in patients with breast cancer, and metastasectomy has been sug- gested to improve survival. Although the role of surgical resection in the treatment of isolated sternal metastasis in breast cancer is recognized, its application in other malignancies has not been appreciated.

Accumulating evidence indicates a potential survival benefit associated with surgical resection of the primary tumor in patients with metastatic RCC. In a randomized, controlled trial of 246 patients with metastatic RCC, median survival was significantly longer among the patients who underwent nephrectomy before receiving interferon alfa therapy than among those who received interferon alfa therapy alone. ${ }^{2}$ Although there clearly could be selection bias in choosing who was enrolled, it was concluded that there was benefit of cytoreduction surgery for RCC in the population studied. In addition, although no prospective studies have been reported, a retrospective analysis of 278 patients with metastatic RCC found the highest survival among those patients who underwent curative metastasectomy (5-year survival of $44 \%$ ). ${ }^{3}$ A similar result was reported for osseous metastasis of RCC, with a 5-year survival of $55 \%$ in the surgical resection group. ${ }^{4}$

Our literature review revealed 8 additional cases of isolated sternal metastasis of RCC (Table 1). Survival cannot be determined because of the short follow-up in most reports; however, our case reviews have indicated at least 3 patients with survivals longer than 5 years. At the MD Anderson Cancer Center, once the primary lesion has been controlled, our recommendation in the Thoracic Surgery Department ideally is to perform sternal metastasectomy if the sternal metastasis is isolated and completely resectable. The addition of chemotherapy before metastasectomy would be dependent on the resectability. The decision to provide systemic therapy is usually made at a multidisciplinary conference on a case-by-case basis.

Although previous reports have demonstrated the resection of sternal metastases, this report demonstrates that despite new biologic therapy (eg, sorafenib), there is still a role for resection in the treatment of carefully selected patients.

\section{References}

1. Ljungberg B, Landberg G, Alamdari FI. Factors of importance for prediction of survival in patients with metastatic renal cell carcinoma, treated with or without nephrectomy. Scand J Urol Nephrol. 2000;34:246-51.

2. Flanigan RC, Salmon SE, Blumenstein BA, Bearman SI, Roy V, McGrath PC, et al. Nephrectomy followed by interferon alfa-2b compared with interferon alfa-2b alone for metastatic renal-cell cancer. $N$ Engl J Med. 2001;345: 1655-9.

3. Kavolius JP, Mastorakos DP, Pavlovich C, Russo P, Burt ME, Brady MS. Resection of metastatic renal cell carcinoma. J Clin Oncol. 1998;16:2261-6.

4. Althausen P, Althausen A, Jennings LC, Mankin HJ. Prognostic factors and surgical treatment of osseous metastases secondary to renal cell carcinoma. Cancer. 1997;80:1103-9. 